\title{
Patterns of uterine rupture in Nigeria: a comparative study of scarred and unscarred uterus
}

\section{Kelechi Ngozi Eguzo ${ }^{1,2 *}$, Adegboyega Kazeem Lawal ${ }^{3}$, Farzana Ali, Chisara Cyprian Umezurike ${ }^{1}$}

\author{
${ }^{1}$ Department of Obstetrics and Gynecology, Nigerian Christian Hospital, Nigeria \\ ${ }^{2}$ Department of Academic Family Medicine, University of Saskatchewan, Canada \\ ${ }^{3}$ College of Pharmacy and Nutrition, University of Saskatchewan, Canada \\ ${ }^{4}$ Department of Community Health and Epidemiology, University of Saskatchewan, Canada
}

Received: 28 May 2015

Accepted: 10 July 2015

\author{
*Correspondence: \\ Dr. Kelechi Eguzo, \\ E-mail: Kelechi.eguzo@usask.ca
}

Copyright: () the author(s), publisher and licensee Medip Academy. This is an open-access article distributed under the terms of the Creative Commons Attribution Non-Commercial License, which permits unrestricted non-commercial use, distribution, and reproduction in any medium, provided the original work is properly cited.

\begin{abstract}
Background: Study aims to explore the differences in presentation, management and outcome of uterine rupture among patients with and without previous uterine scar.

Methods: A 5-year retrospective cross-sectional study of all cases of uterine rupture in Nigerian Christian Hospital. Data was analyzed using descriptive statistics, chi-square and logistics regression.

Results: Incidence of uterine rupture was 14.6 per 1,000 live births ( $n=70 ; 40 \%$ unscarred uterus, 60\% scarred uterus). Lateral rupture was more common with unscarred uterus $(n=27 ; 39 \%)$ compared with anterior rupture in scarred uterus $(n=43 ; 71 \%)$. Rupture of unscarred uterus often involved the cervix and vagina, while scarred uterus involved the bladder $(\mathrm{P}=0.03)$. More cases with unscarred uterus resulted in hysterectomy $(\mathrm{n}=3 ; 14 \%)$ versus scarred uterus $(\mathrm{n}=2 ; 5 \%)$. Unscarred uterus was associated with more haemorrhage $771( \pm 670) \mathrm{mL}$ compared with 403 $( \pm 585) \mathrm{mL}$ for scarred uterus $(\mathrm{P}=0.02)$. Fetal survival was higher with scarred uterus $(\mathrm{P}=0.04)$. There was no significant difference in the incidence of peri-operative complications between the groups.

Conclusion: Rupture of scarred uterus was more common, while rupture of unscarred uterus was associated with more feto-maternal morbidity and mortality. Increase in caesarean section procedures in developing countries could increase the incidence of uterine rupture in these regions, thus prompting a need for improvement in obstetrics care.
\end{abstract}

Keywords: Pregnancy, Uterine rupture, Caesarean section, Hysterectomy, Cross-sectional studies, Developing countries

\section{INTRODUCTION}

Rupture of the gravid uterus has remained a significant obstetric problem on a global scale, especially in the developing world. ${ }^{1}$ It is a major contributor to maternal morbidity and mortality in Nigeria, with incidence ranging from 1 in 87 to 1 in 273 deliveries, and a case fatality rate of over $17 \%$. $^{2,3}$ Previous literature has outlined several risk factors for this condition, including congenital uterine anomalies, feto-pelvic disproportion, multiparity, use of uterotonics for induction/augmentation of labour, placental abnormalities, previous uterine scars (myomectomy and caesarean section), fetal macrosomia, prolonged/obstructed labour, etc. ${ }^{1,4,5}$ Although uterine rupture is rare in the developed world, it remains a public health concern in low-income countries, especially in Sub- Saharan Africa (SSA). The higher incidence in SSA has been attributed to sub-standard obstetric care, poor accessibility and availability of comprehensive Emergence Obstetric Care (EmoC) facilities, as well as poor traditional practices and cultural beliefs. . $^{3,6,7}$

A retrospective study conducted at Mater Misericordiae Hospital in Nigeria (1985-89) found that most cases of rupture $(62.7 \%)$ occurred with intact (unscarred) uterus, while $37.3 \%$ involved scarred uterus. ${ }^{8}$ However, there is 
limited research on the comparison of the patterns of rupture between scarred and unscarred uterus in Nigeria. The objective of this study is to explore the differences in presentation, management and outcome of uterine rupture for patients presenting with previous uterine scar and those without a previous scar. Our findings could potentially guide the early management of cases of uterine rupture, especially in resources-limited settings.

\section{METHODS}

This study was a 5-year retrospective cross-sectional descriptive design, including all cases of uterine rupture $(\mathrm{n}=70)$ in Nigerian Christian Hospital $(\mathrm{NCH})$ between May 2002 and October 2007. NCH is a major referral facility located in a rural part of southeastern Nigeria, and attends to a wide variety of patients, especially those of lower socio-economic status. Teams led by an obstetrician manage labour at this hospital. This hospital conducts about 420 deliveries annually. The attending physician on duty made the diagnosis of uterine rupture clinically based on the presence of clinical signs, including vaginal bleeding, abdominal pain/tenderness and hemoperitoneum. Demographic and clinical Information were collected prospectively using a special data collection instrument designed for this study. Demographic data included maternal age, parity, birth weight, neonatal sex, booking status and place of initial management in labour. Booking status (Yes/No) describes if the woman had attended antenatal care with a skilled provider, irrespective of location.

Clinical data collected comprises the use of uterotonics, duration of labour, maternal and fetal outcomes (dead/alive), estimated blood loss, site of rupture (anterior, posterior or lateral), injury to structures adjacent to the uterus, as well as the type of surgical intervention received (uterine repair, subtotal hysterectomy or total hysterectomy). Information regarding place of initial management, use of uterotonics and estimated duration of labour was self-reported by the patient, while the estimated hemoperitoneum was subjectively reported by the attending surgeon. Self-reported indices were used for some of the data (use of oxytoxics and place of initial presentation), as most patients were referred without proper documentation of care. Duration of labour was estimated based on patients or relatives' recollection of events. The Department of Obstetrics and Gynecology at Nigerian Christian Hospital gave ethical approval for this study. This study builds on a previously published research which focused on the rupture of unscarred uterus. ${ }^{3}$ Patients who had at least one previous uterine surgery (caesarean section or myomectomy) were classified as 'scarred' while those with no prior uterine surgery before the uterine rupture were grouped as 'unscarred'.

Statistical analysis was performed with the SPSS V. 22 (SPSS, Chicago, Ill). Chi-squared and Fisher exact tests were used to assess the statistical significance of the categorical variables; student t-test was used for continuous variables and Mann-Whitney $U$ test was used for ordinal variables. Unconditional Logistics regression was used to estimate the predictors of maternal outcome. Odds ratios (OR) and their corresponding 95\% CI were computed. A P value $<0.05$ was considered statistically significant.

\section{RESULT}

There were 70 cases of uterine rupture during the study period (May 2002 - October 2007) out of a total of 4,786 live births, with an estimated incidence of 14.6 cases per 1000 live births. Forty percent $(n=28)$ had unscarred uterus and $60 \%(n=42)$ had a previous scar on their uterus. Of those with scarred uterus, $41 \%(n=28)$ had one previous caesarean section, while $3 \%(n=2)$ had at least 3 previous uterine surgeries. Table 1 shows the baseline characteristics of the study population. The study groups (scarred versus unscarred uterus) did not differ significantly in terms of age, booking status or place of initial management. However, there was significant difference in parity; rupture of unscarred uterus tends to occur more in nulliparous and grand multiparous women compared with the scarred uterus $(\mathrm{p}<0.01)$.

Most patients with unscarred uterus (39\%; n=11) had lateral rupture while majority of those with scarred uterus $(71 \% ; n=29)$ had anterior rupture. Although oxytocin was the predominant uterotonic implicated in rupture for both groups, more women with unscarred uterus had been exposed to misoprostol compared to those with a scarred uterus $(p<0.01)$. In terms of anatomic complications, more cases with unscarred uterus involved rupture of the cervix and vagina, whereas majority of the cases with scarred uterus involved the bladder $(\mathrm{p}=0.03)$. Rupture involving unscarred uterus was more likely to result in hysterectomy $(14 \% ; n=4)$ compared with $5 \% \quad(n=2)$ among those with scarred uterus, although this was not statistically significant $(\mathrm{p}=0.29)$. Rupture involving unscarred uterus was found to bleed more, with a mean estimated hemoperitoneum of $771( \pm 670) \mathrm{mL}$ compared with $403( \pm 585) \mathrm{mL}$ for the scarred uterus group $(\mathrm{p}=0.02)$. Table 2 shows the clinical/surgical findings for the study population. Only one out of the 70 cases of uterine rupture in this study occurred at Nigerian Christian Hospital. This resulted from poor management of a case vaginal birth after caesarean section (VBAC).

In terms of fetal and maternal outcomes (Table 2), there were interesting differences between the groups. Although most babies did not survive following uterine rupture, this was more common among those involving unscarred uterus $(93 \%)$ than those with a scarred uterus $(73 \%)(\mathrm{p}=0.04)$. No significant difference was found in maternal outcome (dead or alive); although a greater proportion of women with unscarred uterus died $(14 \%, \mathrm{n}=4)$ as compared with $2 \%$ $(n=1)$ among those with scarred uterus. Prolonged labour was a factor in rupture for both groups, with average duration of labour for unscarred uterus as 30 hours $( \pm 25)$ and 29 hours $( \pm 35)$ for those with scarred uterus; but this was not statistically significant either $(\mathrm{p}=0.91)$. 
Table 1: Baseline characteristics of study population.

\begin{tabular}{|c|c|c|c|}
\hline Characteristic & $\begin{array}{l}\text { Unscarred uterus } \\
(\mathbf{n}=28)\end{array}$ & $\begin{array}{l}\text { Scarred uterus } \\
(\mathrm{n}=\mathbf{4 2})\end{array}$ & $\begin{array}{l}\text { P-value } \\
(\alpha=0.05)\end{array}$ \\
\hline Mean age at presentation (Years \pm SD) & $30.9( \pm 4.8)$ & $29.7( \pm 4.7)$ & 0.31 \\
\hline Mean pre-operative HCT (\%) & 31.4 & 32.4 & 0.63 \\
\hline \multicolumn{4}{|l|}{ Booking status (\%) } \\
\hline Booked & $25(89.3 \%)$ & $31(73.85)$ & \multirow{2}{*}{0.11} \\
\hline Unbooked & $3(10.7 \%)$ & $11(26.2 \%)$ & \\
\hline \multicolumn{4}{|l|}{ Parity (\%) } \\
\hline Nulliparous & $4(14.3 \%)$ & 0 & \multirow{4}{*}{$<0.01$} \\
\hline Primiparous & $1(3.6 \%)$ & $18(42.9 \%)$ & \\
\hline Mulitparous & $13(46.4 \%)$ & $20(47.6 \%)$ & \\
\hline Grand multiparous & $10(35.7 \%)$ & $4(9.5 \%)$ & \\
\hline \multicolumn{4}{|l|}{ Place of initial management (\%) } \\
\hline Skilled attendance & $24(85.6 \%)$ & $36(85.6 \%)$ & \multirow{2}{*}{$>0.99$} \\
\hline Unskilled attendance & $4(14.3 \%)$ & $6(14.3 \%)$ & \\
\hline \multicolumn{4}{|l|}{ Distribution of previous scar (\%) } \\
\hline \multicolumn{4}{|l|}{ No previous scar } \\
\hline C-section x 1 & \multirow{4}{*}{$28(41.2 \%)$} & $28(41.2 \%)$ & \\
\hline C-section $\mathrm{x} 2$ or previous rupture & & $10(14.7 \%)$ & \\
\hline C-section $\mathrm{x} 3$ & & $1(1.5 \%)$ & \\
\hline C-section $>3$ & & $1(1.5 \%)$ & \\
\hline
\end{tabular}

Table 2: Summary of clinical and surgical findings.

\begin{tabular}{|c|c|c|c|}
\hline Characteristic & $\begin{array}{l}\text { Unscarred uterus } \\
(\mathrm{n}=28)\end{array}$ & $\begin{array}{l}\text { Scarred uterus } \\
(\mathrm{n}=\mathbf{4 2})\end{array}$ & $\begin{array}{l}\text { P-value } \\
(\alpha=0.05)\end{array}$ \\
\hline \multicolumn{4}{|l|}{ Site of rupture } \\
\hline Anterior & $10(35.7 \%)$ & $29(70.7 \%)$ & \multirow{3}{*}{0.01} \\
\hline Posterior & $7(25.0 \%)$ & $3(7.3 \%)$ & \\
\hline Lateral & $11(39.3 \%)$ & $9(22.0 \%)$ & \\
\hline \multicolumn{4}{|l|}{ Use of uterotonics } \\
\hline Oxytocin & $15(53.6 \%)$ & $39(92.9 \%)$ & \multirow[t]{2}{*}{$<0.01$} \\
\hline Misoprostol & $13(46.4 \%)$ & $3(7.1 \%)$ & \\
\hline \multicolumn{4}{|l|}{ Type of surgical intervention } \\
\hline Uterine repair & $24(85.7 \%)$ & $40(95.2 \%)$ & \multirow{3}{*}{0.29} \\
\hline Subtotal hysterectomy & $3(10.7 \%)$ & $2(4.8 \%)$ & \\
\hline Total hysterectomy & $1(3.6 \%)$ & 0 & \\
\hline \multicolumn{4}{|l|}{ Injury to close organs } \\
\hline No Injury & $14(50.0 \%)$ & $31(73.8 \%)$ & \multirow{6}{*}{0.03} \\
\hline Cervix only & $3(10.7 \%)$ & $4(9.5 \%)$ & \\
\hline Cervix with vagina & $8(28.6 \%)$ & $2(4.8 \%)$ & \\
\hline Bladder & 0 & $3(7.1 \%)$ & \\
\hline Parametrium & 0 & $1(2.4 \%)$ & \\
\hline Gut (Intestines) & $3(10.7 \%)$ & $1(2.4 \%)$ & \\
\hline \multicolumn{3}{|l|}{ Maternal outcome } & \multirow{2}{*}{0.06} \\
\hline Alive & $24(85.7 \%)$ & $41(97.6 \%)$ & \\
\hline
\end{tabular}




\begin{tabular}{|llll|}
\hline \multicolumn{1}{|c|}{ Dead } & $4(14.3 \%)$ & $1(2.4 \%)$ & \\
\hline $\begin{array}{l}\text { Fetal outcome } \\
\text { Alive }\end{array}$ & $2(7.1 \%)$ & $11(26.8 \%)$ & \\
Dead & $26(92.9 \%)$ & $30(73.2 \%)$ & 0.04 \\
\hline Estimated hemoperitoneum (ml \pm SD) & $771.43 \pm 669.61$ & $402.98 \pm 584.77$ & 0.02 \\
\hline Units of blood transfused (Mean \pm SD) & $2.36 \pm 1.59$ & $1.62 \pm 1.61$ & 0.06 \\
\hline Duration of hospital stay (days \pm SD) & $11.59( \pm 6.4)$ & $11.74( \pm 7.9)$ & 0.94 \\
\hline Estimated duration of labor (hours \pm SD) & $29.63( \pm 24.91)$ & $28.63( \pm 34.85)$ & 0.91 \\
\hline Birth weight of baby $(\mathrm{kg} \pm \mathrm{SD})$ & $2.66( \pm 1.40)$ & $3.16( \pm 0.99)$ & 0.10 \\
\hline
\end{tabular}

Table 3 shows the complications of uterine rupture in our study. Most cases of rupture did not have any of the complications that we considered (anemia, sepsis, foot drop and vesico-vaginal fistula [VVF]). Anemia was the most common complication (18.5\% unscarred versus $12.2 \%$ scarred), followed by sepsis (7.4\% unscarred versus $7.3 \%$ scarred). Anatomical complications (foot drop and VVF) were only observed in rupture of unscarred uterus. The differences in complications were not statistically significant $(\mathrm{p}=0.23)$. Anecdotal evidence from our practice shows that VVF and foot drop are not common among patients who had proper antenatal and peripartum care.

Table 3: Patterns of post-operative complications of uterine rupture.

\begin{tabular}{|c|c|c|c|}
\hline Complications & $\begin{array}{l}\text { Unscarred } \\
\text { uterus } \\
(\mathbf{n}=\mathbf{2 8})\end{array}$ & $\begin{array}{l}\text { Scarred } \\
\text { uterus } \\
(n=42)\end{array}$ & $\begin{array}{l}\text { P-value } \\
(\alpha=0.05)\end{array}$ \\
\hline No complications & $17(63.0 \%)$ & $33(80.5 \%)$ & \multirow{5}{*}{0.23} \\
\hline Anemia & $5(18.5 \%)$ & $5(12.2 \%)$ & \\
\hline Sepsis & $2(7.4 \%)$ & $3(7.3 \%)$ & \\
\hline Foot drop & $2(7.4 \%)$ & $0(0.0 \%)$ & \\
\hline VVF & $1(1.5 \%)$ & $0(0.0 \%)$ & \\
\hline
\end{tabular}

We used logistics regression to identify the predictors of maternal outcome for women presenting with uterine rupture, but there was no difference in maternal outcome based on place of initial presentation (skilled vs. unskilled attendance) $(\mathrm{p}>0.9)$, nor on the use of uterotonics; oxytocin and misoprostol), $(\mathrm{p}=0.13)$.

\section{DISCUSSION}

This study explored comparatively the differences in presentation, management and outcomes of uterine rupture for patients presenting with previous uterine scar and those without a previous scar. Of the 70 patients involved in this study, there were fewer occurrences $(40 \% ; 28 / 70)$ among those with unscarred uterus compared with $60 \%$ (42/70) for those with scarred uterus. This is at variance with the study published by Eze et al, ${ }^{8}$ who reported a higher incidence of rupture $(60 \%)$ among unscarred uterus. This may be related to the high caesarean section rate in our center. ${ }^{9}$ As the caesarean delivery rate increases in the developing world without corresponding improvement in the level of obstetric care, uterine rupture in women with scarred uterus may be on the rise..$^{10}$ Although women in both groups were similar (Table 1), rupture of unscarred uterus occurred more frequently among nulliparous and grand-multiparous women $(\mathrm{p}<0.01)$. All the four cases involving nulliparous women in our study had unscarred uterus (Table 1). This is at variance with the general anecdotal thinking that uterine rupture is largely unknown among the nulliparous women.

Historically there is a variation in the global incidence of uterine ruptures, with higher morbidity and mortality rates predominantly reported in developing countries. ${ }^{11} \mathrm{We}$ observed that rupture in an unscarred uterus is a serious condition associated with a higher mortality rate and complications during labour, compared to scarred uterus. Out of 28 women with an unscarred uterus, $14.3 \%(n=4)$ died from this condition compared to only $2.4 \%(n=1)$ among those with a previous scar, even though there was no difference in the estimated time to labour for both groups ( $p>0.91$ ). The overall case fatality rate in our study (7.1\%) was significantly lower than the $17 \%$ previously reported in the literature by Eguzo et al. ${ }^{3}$ This may be attributed to the current approach in the management of obstetrics emergencies at our hospital. At $\mathrm{NCH}$, our approach is to offer our patients all the care required (including surgery) within 30 minutes of admission, irrespective of their financial status. This patient-first, payment-later model has been the hallmark of $\mathrm{NCH}$ services since 1965. Four out of the five deceased patients in the study were initially managed by 'unskilled personnel' (traditional birth attendants, maternity homes, or at churches) prior to being transferred to the $\mathrm{NCH}$. This illustrates the significant danger of unskilled attendants at labour that was previously highlighted by Eguzo et al. ${ }^{3}$ The cultural aversion to caesarean delivery in Nigeria still exist even after prior caesarean section, hence women with past history of caesarean deliveries still patronize 'unskilled personnel' with the aim of avoiding further procedures in the future.

Surgical management of uterine rupture is diverse, depending on the clinical presentation, the patient's future reproductive desires and skill of the attending surgeon. ${ }^{11}$ In our experience, uterine repair was the most common modality of treatment. This mode of treatment not only 
shortens the operating time but also preserves fertility in the affected women. More cases involving unscarred uterus had peripartum hysterectomy (sub-total and total) compared with the scarred uterus. These differences however, were not statistically significant $(\mathrm{p}=0.30)$. Two of the 5 cases of maternal mortality in the study were managed by peripartum hysterectomy (Table 2). Uterine repair was not performed in those cases because the uterus was friable or necrotic due to overwhelming sepsis.

Furthermore, we observed that the estimated blood loss was significantly higher for unscarred uterus $771.43 \mathrm{~mL}$ $( \pm$ 669.61) compared with scarred uterus $402.98 \mathrm{~mL}$ $( \pm 584.77),(\mathrm{P}=0.02)$. This finding is similar to the pattern of postpartum hemorrhage reported by Ofir et al, when they compared uterine rupture between scarred and unscarred uterus among Israeli women. ${ }^{11} \mathrm{We}$ assume that this difference exist because of poor vascularization of the scar tissue, which is characteristic of a scarred uterus compared with an unscarred one. The anterior aspect of the uterus was the most common site of rupture (scarred uterus $35.7 \%$ vs. unscarred uterus $70.7 \%$ ). It is likely that anterior rupture occurred more frequently for scarred uterus, as this must have been preceded by scar dehiscence. However, we noticed more posterior rupture in unscarred uterus $25.0 \%$ compared with $7.3 \%$ for scarred uterus. Most cases did not present with injuries to adjoining structures (unscarred $50.0 \%$ vs. scarred $73.8 \%$ ). However, more cases with scarred uterus had bladder involvement (7.1\% vs. $0 \%$ unscarred), while unscarred uterus had more injuries to the small intestines (10.4\%). Rupture involving the cervix and/or vagina were more common with unscarred uterus, similar to what has been reported in the literature. ${ }^{11}$ These differences were statistically significant $(\mathrm{p}=0.03)$.

Overall, there were more adverse outcomes associated with uterine rupture involving unscarred uterus than scarred uterus. Also, more fetal deaths were associated with unscarred uterus $(92.9 \% ; 26 / 28)$ compared with scarred uterus $(73.2 \% ; 31 / 42), \mathrm{p}=0.04$. This finding is striking, given that the average fetal birth weight was higher for scarred uterus $3.2 \mathrm{~kg}( \pm 0.9)$ compared with 2.4 $\mathrm{kg}( \pm 1.4)$ for unscarred uterus, $(\mathrm{p}=0.02)$. The pattern of complications that we observed in this study, with anemia ranking highest, was similar to that reported by Mbamara et $\mathrm{al}^{12}$ who researched into uterine rupture in Enugu, southeastern Nigeria. This study did not explore other underlying factors that could account for the complications. The higher prevalence of anatomical complications (foot drop and VVF) observed in this study further strengthens our earlier observation that rupture of unscarred uterus is a greater catastrophic event compared with scarred uterus. One limitation of this study is the sample size. A sample size of 78 cases (39 in each group) would have been more appropriate to detect significant differences between the groups, assuming a power of $80 \%$ with error rate of $5 \%$; implying that our skewed sample could have biased the findings in this study. This limitation implies the need for a larger sample size in future research investigating comparative differences between scarred and unscarred uterus.

\section{CONCLUSION}

Rupture of scarred uterus was more common, while rupture in an unscarred uterus was however associated with more peripartum hysterectomy, maternal morbidity and fetal loss. As the caesarean delivery rates increases in the developing world without corresponding improvement in the level of obstetric care, the incidence of uterine rupture may be on the rise especially in women with scarred uterus. Thus, there is a need for improvement in access to quality obstetrics care in Nigeria.

\section{ACKNOWLEDGEMENTS}

The authors would like to acknowledge the support of the staff at Nigerian Christian Hospital, especially those working in the Maternity and Theatre Units.

Funding: No funding sources Conflict of interest: None declared

Ethical approval: The study was approved by the Institutional Ethics Committee

\section{REFERENCES}

1. Ezegwui HU, Nwogu-Ikojo EE. Trends in uterine rupture in Enugu, Nigeria. Journal of obstetrics and gynaecology: J Obstet Gynaecol. 2005;25:260-2.

2. Ebeigbe PN, Enabudoso E, Ande A. Ruptured uterus in a Nigerian community: a study of sociodemographic and obstetric risk factors. Acta Obstet Gynecol Scand. 2005;84:1172-4.

3. Eguzo KN, Umezurike CC. Rupture of unscarred uterus: a multi-year cross-sectional study from Nigerian Christian Hospital, Nigeria. Int J Reprod Contracept Obstet Gynecol. 2013;2:657-60.

4. Justus Hofmeyr G, Say L, Metin Gülmezoglu A. Systematic review: WHO systematic review of maternal mortality and morbidity: the prevalence of uterine rupture. BJOG. 2005;112:1221-8.

5. Mukasa PK, Kabakyenga J, Senkungu JK, Ngonzi J, Kyalimpa M, Roosmalen VJ (2013) Uterine rupture in a teaching hospital in Mbarara, western Uganda, unmatched case-control study. Reprod Health 10:29.

6. Aboyeji AP, Ijaiya MDA, Yahaya UR. Ruptured uterus: a study of 100 consecutive cases in Ilorin, Nigeria. J Obstet Gynaecol Res. 2001;27:341-8.

7. Eze J, Ibekwe P. Uterine rupture at a secondary hospital in Afikpo, Southeast Nigeria. Singapore Med J. 2010;51:506-11.

8. Ozumba BC, Uchegbu H. Incidence and management of obstructed labour in eastern Nigeria. Aust N Z J Obstet Gynaecol. 1991;31:213-16.

9. Umezurike CC, Feyi-Waboso PA, Adisa CA. Peripartum hysterectomy in Aba southeastern 
Nigeria. Aust N Z J Obstet Gynaecol. 2008;48:5802.

10. Umezurike C, Feyi-Waboso P. Placenta accreta and the developing world-A review. East Afr Med J. 2010;87:513-20.

11. Ofir K SE, Levy A, Katz M, Mazor M. Uterine rupture: differences between a scarred and an unscarred uterus. Am J Obstet Gynecol. 2004;191:425-9.
12. Mbamara S, Obiechina N, Eleje G. An analysis of uterine rupture at the Nnamdi Azikiwe University Teaching Hospital Nnewi, Southeast Nigeria. Niger J Clin Pract. 2013;15:448-52.

Cite this article as: Eguzo KN, Lawal AK, Ali F, Umezurike CC. Patterns of uterine rupture in Nigeria: a comparative study of scarred and unscarred uterus. Int J Reprod Contracept Obstet Gynecol 2015;4:1094-9. 